
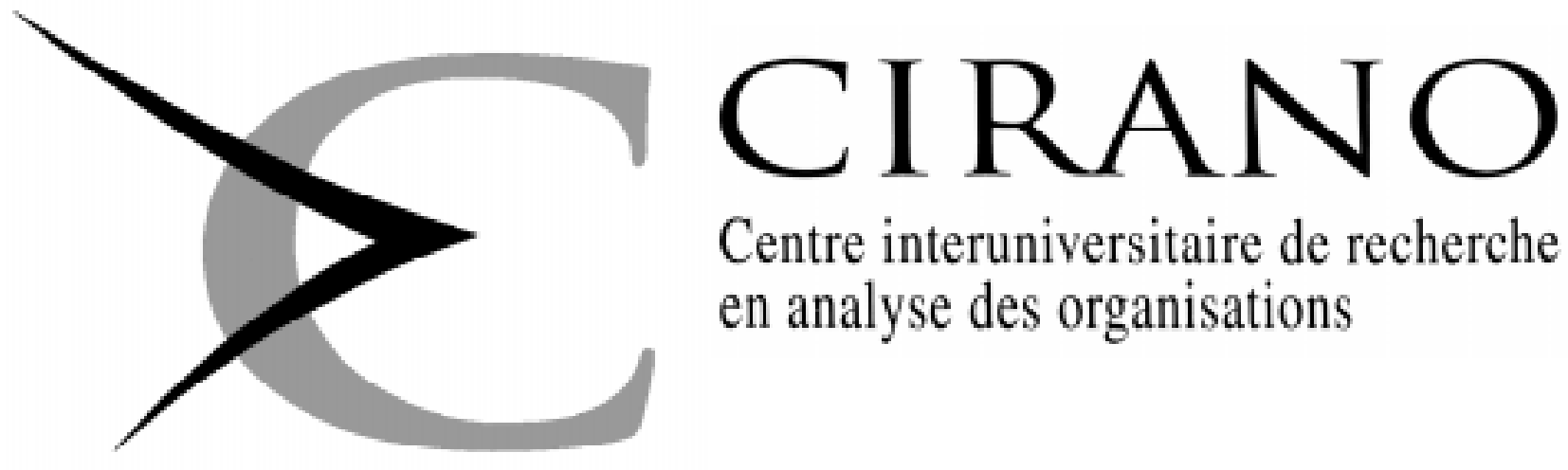

Centre interuniversitaire de recherche en analyse des organisations

Série Scientifique

Scientific Series

98s-18

Managing the Risk of IT

Outsourcing

Benoit A. Aubert, Sylvie Dussault,

Michel Patry, Suzanne Rivard 


\section{CIRANO}

Le CIRANO est une corporation privée à but non lucratif constituée en vertu de la Loi des compagnies du Québec. Le financement de son infrastructure et de ses activités de recherche provient des cotisations de ses organisations-membres, d'une subvention d'infrastructure du ministère de l'Industrie, du Commerce, de la Science et de la Technologie, de même que des subventions et mandats obtenus par ses équipes de recherche. La Série Scientifique est la réalisation d'une des missions que s'est données le CIRANO, soit de développer l'analyse scientifique des organisations et des comportements stratégiques.

CIRANO is a private non-profit organization incorporated under the Québec Companies Act. Its infrastructure and research activities are funded through fees paid by member organizations, an infrastructure grant from the Ministère de l'Industrie, du Commerce, de la Science et de la Technologie, and grants and research mandates obtained by its research teams. The Scientific Series fulfils one of the missions of CIRANO: to develop the scientific analysis of organizations and strategic behaviour.

\section{Les organisations-partenaires / The Partner Organizations}

-École des Hautes Études Commerciales

-École Polytechnique

-McGill University

- Université de Montréal

-Université du Québec à Montréal

-Université Laval

-MEQ

- MICST

-Avenor

- Banque Nationale du Canada

-Bell Québec

- Caisse de dépôt et placement du Québec

- Fédération des caisses populaires Desjardins de Montréal et de l'Ouest-du-Québec

-Hydro-Québec

- Industrie Canada

- Microcell Labs inc.

- Raymond, Chabot, Grant, Thornton

- Scetauroute

- Société d'électrolyse et de chimie Alcan Ltée

-Téléglobe Canada

-Ville de Montréal

Ce document est publié dans l'intention de rendre accessibles les résultats préliminaires de la recherche effectuée au CIRANO, afin de susciter des échanges et des suggestions. Les idées et les opinions émises sont sous l'unique responsabilité des auteurs, et ne représentent pas nécessairement les positions du CIRANO ou de ses partenaires.

This paper presents preliminary research carried out at CIRANO and aims to encourage discussion and comment. The observations and viewpoints expressed are the sole responsibility of the authors. They do not necessarily represent positions of CIRANO or its partners.

ISSN 1198-8177 


\title{
Managing the Risk of IT Outsourcing
}

\author{
Benoit A. Aubert ${ }^{\dagger}$, Sylvie Dussault ${ }^{\ddagger}$, Michel Patry, \\ Suzanne Rivard"
}

Résumé / Abstract

\begin{abstract}
L'impartition des services informatiques, même si elle peut entrainer de nombreux bénéfices, implique un risque. Comme tout type d'investissement, ce risque doit être évalué et géré. Cet article propose un cadre d'analyse pour le risque d'impartition des services informatiques, et évalue ce cadre à l'aide d'une étude de cas. Ce cas présente deux décisions d'impartition de services informatiques, dans le domaine de l'assurance. Le niveau de risque de chaque décision est évalué et les mécanismes permettant de gérer ce risque sont présentés. Les résultats montrent que, en détaillant les facteurs de risque et les événenents correspondants, il est possible de cibler les éléments les plus risqués et de réduire le risque à un niveau acceptable.
\end{abstract}

While it can bring several benefits, IT outsourcing entails some risks. As it is the case in other types of investments or business ventures, the risk associated to an IT outsourcing project must be evaluated and managed. This paper proposes a framework for the management of IT outsourcing risk, and assesses the usefulness of the framework using data gathered about two cases of system development outsourcing. After providing a conceptual definition of risk and of risk exposure, the paper presents the proposed risk management framework. The two cases are then described along with the evaluation of the level of risk exposure of each, and the risk management mechanisms that were included in the contracts. The results of the study suggest that by charting the various items that contribute to risk exposure, and by specifically applying the appropriate mechanisms that can target the elements with the higher levels of risk exposure, outsourcing risk can be adequately managed.

Mots Clés : $\quad$ Sous-traitance des systèmes informatiques, gestion du risque des systèmes informatiques, théorie de l'agance, économie des coûts de transaction, étude de cas

\footnotetext{
" Corresponding Author: Benoit A. Aubert, CIRANO, 2020 University Street, 25th floor, Montréal, Qc, Canada H3A 2A5 Tel: (514) 985-4024 Fax: (514) 985-4039 e-mail: aubertb@ cirano.umontreal.ca

École des Hautes Études Commerciales and CIRANO

* Université Laval

$\S$ École des Hautes Études Commerciales and CIRANO

" École des Hautes Études Commerciales and CIRANO
} 
Keywords : $\quad$ Outsourcing of IS, IS risk management, agency theory, transaction cost economics, case study

JEL : L23 


\section{Introduction}

"You'll never have all the information you need to make a decision - if you did, it would be a foregone conclusion, not a decision" [22, p.156].

Risk is inherent to almost any business decision. New product development, capital investments, and implementation of state of the art technology are often used as examples of risky business ventures; while they may lead to major benefits, they may also result in important losses. Outsourcing decisions, and contractual arrangements of the type required by an IT outsourcing deal, are another example of a risky business endeavor. While it can lead to lower costs, economies of scale, access to specialized resources, and new business ventures $[15,16]$, outsourcing can have unwanted outcomes such as escalating costs, diminishing service levels, and loss of expertise, to name a few $[11,13,17]$.

This is not to say that outsourcing is bad in itself. It only means that, as in other risky business ventures, risk assessment and risk management are important contributors to the success of an IT outsourcing venture [27]. This paper proposes a framework for the management of IT outsourcing risk, and assesses the usefulness of the framework in the particular context of two systems development outsourcing contracts.

The paper first defines the concept of risk exposure which is a function of two variables, the probability of undesirable outcomes and the potential loss related to the occurrence of the outcomes. The risk management framework is then presented, and its relevance is assessed by analyzing two systems development outsourcing contracts.

\section{Risk exposure of IT outsourcing}

Following Boehm [8], risk is defined here as "the possibility of loss or injury", that is, the probability of occurrence of undesirable outcomes. Boehm also introduces the concept of risk exposure which takes into account the importance of the loss due to the occurrence of undesirable outcomes. Risk exposure is then defined as follows :

$$
\mathrm{RE}=\mathrm{P}(\mathrm{UO}) * \mathrm{~L}(\mathrm{UO})
$$


where $\mathrm{RE}$ is the risk exposure, $\mathrm{P}(\mathrm{UO})$ the probability of an undesirable outcome, and $\mathrm{L}(\mathrm{UO})$ the loss due to the undesirable outcome $[8,21,31]$.

Figure 1 illustrates the concept of risk exposure. Consider the following undesirable outcome which is sometimes associated with IT outsourcing : service debasement. There exist four possible scenarios for this outcome. In the first scenario (low RE), the characteristics of the outsourcing contract are such that there exists a small probability that it will result in poor service quality. Moreover, in this example, it is estimated that no serious loss is related to poor service quality. Consequently, the level of risk exposure of the project (with respect to this undesirable outcome) is low. In the second scenario (high RE), both the probability of service debasement and the loss related with poor service quality are high. In such a case, there is a high level of risk exposure. The other two scenarios will result in medium levels of risk exposure. In one case, the probability of service debasement is high while the potential loss related to it is low. In the other instance, there exists only a small probability of service debasement, yet the loss related to this outcome is high.

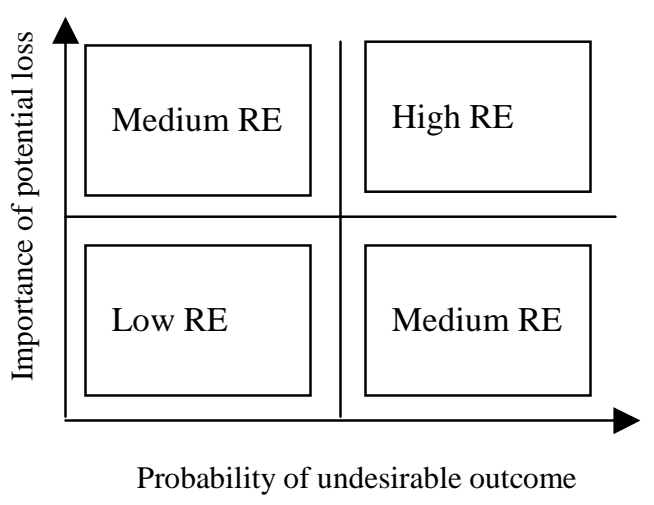

Figure 1: Risk exposure

The loss due to a given undesirable outcome can be approximated either via quantitative analysis (for instance, by evaluating the amount of sales lost due to disruption of service to customers) or via qualitative assessment (for instance, by using Likert scales) [5, 28].

In certain circumstances, the probability of occurrence of an undesirable outcome can be estimated on the basis of the past performance of the object 
under study [20]. However, in several areas such an assessment is difficult, if not impossible, to perform [5]. Consequently, several risk assessment methods adopt the approach of approximating the probability of an undesirable outcome by identifying and assessing the characteristics of a situation that are likely to influence the occurrence of the outcome [2,5,7]. These characteristics are labeled risk factors.

This approach was adopted by Aubert, Patry and Rivard [3] who reviewed the IS and the industrial organization literature, and identified the most often cited undesirable outcomes of IT outsourcing, as well as the main risk factors related to each. Table 1 summarizes their findings.

Table 1: Components of risk exposure of IT outsourcing

\begin{tabular}{|c|c|}
\hline Undesirable outcomes & $\begin{array}{l}\text { Risk factors leading to } \\
\text { undesirable outcomes }\end{array}$ \\
\hline $\begin{array}{l}\text { Unexpected transition and } \\
\text { management costs }[9,11,24]\end{array}$ & $\begin{array}{l}\text { - Lack of experience and expertise of } \\
\text { the client with the activity }[11,18] \\
\text { - Lack of experience with outsourcing } \\
\text { [11] }\end{array}$ \\
\hline Lock-in [25] & $\begin{array}{l}\text { - } \\
\text { - }\end{array}$ \\
\hline $\begin{array}{l}\text { Costly contractual amendments } \\
\text { [11] }\end{array}$ & $\begin{array}{ll}\text { - } & \text { Uncertainty }[1,6] \\
\text { - } & \text { Technological discontinuity [18] }\end{array}$ \\
\hline Disputes and litigation $[4,17]$ & $\begin{array}{l}\text { - Measurement problems }[1,6] \\
\text { - Lack of experience and expertise of } \\
\text { the client and/or of the supplier with } \\
\text { outsourcing contracts }[11,18]\end{array}$ \\
\hline Service debasement $[4,17]$ & $\begin{array}{l}\text { - Interdependence of activities }[3,19] \\
\text { - Performance ambiguity }[11,12] \\
\text { - Lack of experience and expertise of } \\
\text { - } \text { the supplier with the activity [11] } \\
\text { - Supplier size [11] } \\
\text { Supplier financial stability [11] }\end{array}$ \\
\hline Cost escalation $[17,18]$ & $\begin{array}{l}\text { - Opportunism of the supplier }[12,29] \\
\text { - Lack of experience and expertise of } \\
\text { the client with contract management } \\
{[11,18]}\end{array}$ \\
\hline $\begin{array}{l}\text { Loss of organizational } \\
\text { competencies }[10,11,17,30]\end{array}$ & $\begin{array}{l}\text { Proximity of the core competencies } \\
{[26]}\end{array}$ \\
\hline
\end{tabular}




\section{A Risk Management Framework}

The objective of risk management is to reduce the level of risk exposure of a given business venture. Given an expected level of benefits from an outsourcing strategy, a rational, profit maximizing, and risk-averse decision maker wishes to minimize the risk exposure of the project or the strategy. A boundedly rational decision maker may wish, for the same given level of benefits, to bring the level of risk exposure below some threshold or acceptable level (this is a "satisficing" decision rule, in Herbert Simon's terminology ). In both cases, reduction of the level of risk exposure can be achieved in two ways: either by reducing the losses associated with the undesirable outcomes, or by lowering the expected probability of occurrence of such outcomes.

This is shown in Figure 1. Examination of this figure also suggests that in order to be effective, a risk management strategy has to focus on the appropriate component of risk exposure. For instance, in a scenario where the probability of an undesirable outcome is low but the loss due to the outcome is high (upper left quadrant), a risk management approach which would be aimed at reducing the -already low- probability of the outcome would not be very effective, or could be prohibitively costly. Accordingly, the risk management framework illustrated in Figure 2 proposes four generic risk management strategies.

Strategy I is appropriate for a medium level of risk exposure, and focuses on reducing the importance of the loss related to the occurrence of an undesirable outcome.

Assume that reducing the probability of occurrence of a given outcome incurs costs. Further assume that the marginal cost of reducing that probability is increasing. This means that any reduction of the probability of an occurrence below some level entails exponentially rising costs. It is therefore never desirable to drive that probability to zero. In fact, casual empiricism leads one to argue that this is plainly impossible.

As a result, for an outcome with a very low probability, reduction in risk exposure is most economically pursued through a strategy aimed at bringing the consequences of the outcome within reasonable bounds. Strategy I is the Tolerance Strategy: the decision maker prepares himself to cope with the (unlikely) occurrence of an undesirable outcome.

Buying insurance is the archtypical example of this strategy. Many deflection mechanisms, which essentially transfer to third parties the costs of coping with undesirable consequences, fall into that category. Incentive contracts, 
wherein the amount due to the outsourcer will depend on the quality of the service rendered, are an example. Bonds and warrants play a similar role. Some contingency planning strategies also help in bringing down the level of losses. The outsourcer who maintains an idle or underutilized capacity to perform certain tasks in order to be ready in case of a contract failure or disruption bears a (rather small) recurrent cost in exchange or a reduction in the level of losses.

Strategy II is the mirror image of Strategy I: it refers to all measures aimed at reducing the probability of an undesirable outcome. In situations where losses are not very large, but the probability of occurrence is relatively high, it appears economical to reduce this probability.

An example will illustrate how this can be achieved. Consider a case where the potential loss associated with service debasement is moderate, but the probability of its occurrence is high, corresponding to the lower right quadrant of Figure 1. Suppose that, as suggested by the risk management framework, the probability of service debasement was estimated by assessing each of the risk factors associated to this outcome (see Table 1), and were found as follows : (1) a high degree of interdependence between the outsourced activities and those kept in-house; (2) the potential supplier lacks experience and expertise with the activities to be outsourced; (3) the potential supplier is a small firm, and (4) is not financially stable.

In this case, applying Strategy II would mean to carefully choose the activities to be outsourced in order to reduce the degree of interdependency, and to select a financially stable supplier, with sufficient resources to provide a good level of services, and with an appropriate level of experience and expertise with the activities to be outsourced.

This will be feasible when the behavior of the partners, that of the outsourcer and of the supplier, impinge in predictable ways on the probability of occurrence. This is the very reason why insuring against such losses is difficult: the insurer faces the classical situation of moral hazard. By fully insuring the outsourcer, the insurer diminishes the incentive to behave in a prudent fashion.

Strategy II could be termed the Strategy of Prudence: the outsourcer actively tries to manipulate the probability that the undesirable outcome will occur, mainly through its own behavior, and by properly inducing and enticing an appropriate response from the supplier, through incentive contracts, for instance. 
Strategy III definitely corresponds to a risky outsourcing strategy. The rational outsourcer will persist only if he or she envisages large payoffs, for the risk exposure is high. Once the decision to go ahead has been taken, the outsourcer tries to deal with both high probabilities of a negative outcome and important losses. Thus, in addition to actions taken to lessen the probability of occurrence of an outcome, the outsourcer will seek to increase his or her tolerance. Hence, this is our Mixed Strategy.

Strategy III naturally involves a mix of deflection, mitigation and contingency planning moves. Deflection calls for some form of insurance : through an explicit contract, or implicitly through the reputation of the supplier. Mitigation implies that the outsourcer will try to actively reduce the likelihood of an undesirable outcome. Contingency planning implies, while the probability and the impact of the undesirable outcome may remain unchanged, the search for alternative courses of action that may be taken if the occasion arises [28]. Parallel sourcing is an example of such an alternative course of action.

Finally, Strategy IV is mainly a Monitoring Strategy. It is well suited to situations in which both the probability of occurrence and the losses are deemed relatively small. Any effort to reduce either the probability of an outcome or its impact would only be marginally profitable. This calls for two things: first, it is important to periodically reassess the level of risk exposure in order to determine if it has remained the same; and secondly, the outsourcer should make sure that all the "standard safeguards" are well in place. The situation does not warrant, however, that important resources be devoted to the design of sophisticated instruments or contracts to deal with the situation.

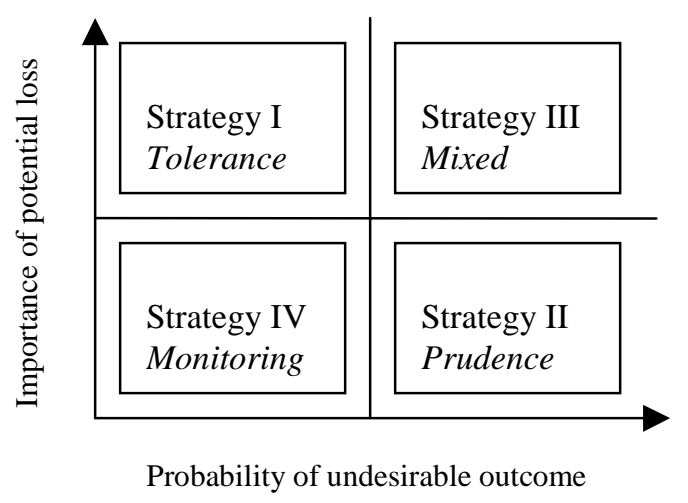

Figure 2: A Risk Management Framework 
The following section illustrates how one outsourcer dealt with risk exposure in two major outsourcing projects.

\section{Methodology}

A case study was conducted as a preliminary test for the usefulness and the adequacy of the proposed framework. The study was conducted in a large insurance company which sells individual as well as group insurance products. The company employs 3500 people; its operation centers are located in four cities, in two different countries. The company currently uses over 200 information systems to support its business needs.

For the purposes of the study, two system development outsourcing decisions and the resulting contracts were analyzed : the Year 2000 project and the Application development partnership project. For each outsourcing decision, data were collected from the following sources : requests for proposals, supplier proposals, contracts and addenda, and interviews with managers who had been involved in the decision process and managers in charge of overseeing the contracts.

Using this data, the level of risk exposure of each outsourcing project was estimated. To do so, the importance of the potential loss due to the occurrence of each undesirable outcome listed in Table 1 was first evaluated, on a 1 (very low) -7 (very high) Likert scale. Then, the probability of occurrence of this outcome was approximated - on a 1-7 Likert scale - by assessing the importance of each of the risk factors associated with the outcome (see Table 1). As shown in Figure 3, this resulted in seven data points for each outsourcing project (one for each undesirable outcome). The following section presents the essential elements of this assessment of risk exposure.

\section{An Exercise in the Evaluation of Risk Exposure}

\section{Contract 1 - Year 2000}

As it is the case in numerous firms, a large proportion of the systems used by the insurance company do not support the four digits required to handle the year 2000 date format. The firm estimated that the year 2000 would have major impacts on 36 of its systems and minor impacts on 29 others. Twenty four additional systems would soon be replaced by new versions that would support the four-digit year and 46 others remained to be evaluated. The estimated effort required for migrating all the systems through the millenium was more than 25000 person-days. The insurance company did not have the 
skills, the expertise, nor the human resources available in-house to undertake this endeavor. It was decided to rely on an external provider to perform the Y2000 conversion.

In this case, the potential loss associated to transition and management costs was estimated as being rather low. The negotiation process mobilized several executives who prepared the request for proposals and evaluated the suppliers' propositions. The company evaluated that the equivalent of one hundred person-days were spent on those activities. In addition, legal fees (minor) were paid to a law firm for writing the contract. Since the entire project was estimated to require 25000 person-days, the anticipated transition costs represent approximately $0.4 \%$ of the overall project cost. The ongoing management costs were also expected to be minimal. The outsourced activiteies are self-contained and clearly identified. A committee would meet periodically to ensure that the schedule is respected. The main risk factor that can lead to unexpected transition and management costs is the lack of experience and expertise of the client with the activity. In this case, the client has extensive experience in software development. It is a large organization that develops software on an ongoing basis. Therefore the potential loss and the probability of such a loss were rated very low (1-1) - see Figure 3.

The potential loss associated with lock-in is substantial. If the supplier were to renegotiate the contract, threatening the client to renege on its promise to deliver the Y2000 modifications on time, a lock-in situation would be created. Such a threat, if credible, could force the client to accept paying a major premium to ensure that the modifications are delivered on time. The Y2000 imposes a strict deadline for project completion. However, this loss is limited because the contract is not renewable. The supplier would not be able to keep the client locked-in for a long time since this contract, by its essence, will end within two years from the signature date. The potential loss was evaluated as medium-high (4). The probability of such a loss is rather low. Many suppliers can perform this contract. Six proposals were received before the current supplier was selected, and the Y2000 modifications are not very specific in nature. The required technical knowledge is common to many suppliers. Therefore, the probability of the negative outcome was rated as very low (1).

The third potential loss evaluated is the occurrence of costly contractual amendments. In this case, the potential amendments were minor (2). The work is very well defined (upgrading the system for Y2000) and potential changes would be minor ones. The probability of having such changes is very low (1). The systems requiring modifications are carefully examined by the vendor and the client before the signature of the contract and therefore there is 
little uncertainty regarding the work required. The systems are not replaced, they are modified. There is no technological discontinuity involved.

Any dispute or litigation is costly. Since this type of software modification is rather well-structured, it would ease the litigation process by facilitating the demonstration of a party's argument. The costs of litigation were estimated as medium-low (3). Litigation is often due to a lack of clear and agreed-upon measures to evaluate the activities, and to a lack of experience with outsourcing from the parties. In this case, measures exist and are agreed upon. Moreover, both parties (client and vendor) have extensive experience with outsourcing of IS activities. Therefore, the probability of litigation is very low (1).

In this project, of the most feared outcome is service debasement. In this case, poor service quality would be costly (5). A deterioration of the level of service would threaten the ability of the insurance company to keep a steady course through year 2000. Poor service would impede many day-to-day operations and generate numerous errors that would be costly to correct. However, the probability of such an event is very low (1): the supplier chosen is a large and established firm, competent and experimented with this type of activity. Moreover, the Y2000 activities are very independent from the other activities. Finally, service will not be affected while the outsourcer performs its tasks.

A frequently mentioned outcome of IT outsourcing is cost escalation. The importance of the potential loss associated with this outcome was evaluated as medium (4). Effort could naturally be overestimated. This increased cost is however limited because the contract itself is limited in time (until year 2000). Therefore, were the supplier be tempted to inflate its prices, it could only do so for two years. The probability that such an escalation occurs is moderate (4). Prices are subject to supply and demand and, in the past year, there has been a significant increase in demand for Y2000 expertise. This leads to price increases and could drag up the costs of the services. The opportunism of the supplier has more leeway to manifest itself. But this possibility is moderated by the experience of the client with outsourcing and with vendors, helping the client in overseeing the supplier's work and preventing cost inflation.

Finally, the last undesirable consequence is the loss of organizational competencies. In this case, it is very low (1). The client did not have specific Y2000 competencies in the beginning. And the skills involved are not a highly valued expertise in the organization. The skills that are potentially lost are not precious. The probability of loosing valued skills is also very low (1) since Y2000 skills are far from the core competencies of the organization. 


\section{Contract 2 - Application development partnership}

The second project is called the Application development partnership project. The insurance company was dealing with approximately 65 different software development firms, even it had a large internal staff developing information systems. It was decided to stop awarding contracts to so many different suppliers and to select one (or maybe a few) application partner that would invest time and resources in understanding the company and its needs. It was believed that doing so would enable the firm to receive the same benefits (ex. market price, access to outside expertise) as in the current situation (with numerous vendors) while enjoying a more personalized and more dedicated service from a partner expecting to develop many projects for its client. Dedicated partners were presumed to assume more responsibility and to shoulder more risks for their client.

The unexpected transition and management costs of this outsourcing arrangement are minimal (1). Negotiation time was evaluated at approximately 110 person-days, to which the legal fees limited to contract verification and authentication were added. This represents a very minor percentage of the contract overall value: execution of the contract involves a minimum of 10000 person-days per year. The probability associated with this potential loss is also very low (1). As mentioned previously, the client is experienced with regards to software development, enabling it to foresee transition and management costs.

The potential lock-in of the client with a vendor would be costly (6). If such a situation arose, the client would be trapped is a situation where it would be attached to a particular supplier. Because it is a large organization that undertakes many software development projects yearly, such a situation would permit the vendor to extract a quasi rent from the client over a long period. But the probabilities that such a situation occurs are low (2). Although the projects involve some specific knowledge, linked to the firm's unique activities, many suppliers could perform this work. After the request for proposals, twenty-nine suppliers submitted offers. Even if there was some disparity among the quality of the offers, the number indicates that many suppliers can provide those services. Of course, once a supplier is chosen and has begun providing the service, this supplier gains a better knowledge of the company, which gives him a competitive advantage over potential supliers.

Costly contractual amendments are the most important threat in this case. Changes in specifications, technology and efforts required from the vendor are very likely. The insurance business is information intensive and modifications in the technology infrastructure are common and often 
significant. Therefore, a strict contract would require major modifications when new technology is introduced, or when competitors use an existing one in new ways to gain competitive advantage. Those actions are very difficult to foresee and preclude the use of complete contracting. The potential loss associated with such modifications is high (6). Also, the probability of such modifications is significant. It was valued at (3) for the following reasons. In the short term, the development agenda is fairly well defined, presenting low uncertainty and subject to no major changes in the technology used. In the longer term, the uncertainty is much higher and the probability of technological discontinuity increases significantly. Therefore, the overall probability is medium-low.

The potential loss associated with dispute and litigation, like in the first contract, was evaluated as medium-low (3) for the same reasons. However, the probability of such event is slightly higher in this case (2). The measures available for this contract are less well-defined and the work itself is less selfcontained. Performance ambiguity represents a greater problem here. This is tampered by the expertise of the parties. The suppliers having made the offers were experienced, as was the client.

The potential loss due to service debasement was estimated as medium-low (3). If the software developed was not up to the client's expectations, service would be affected gradually. The systems in place are up to date and running properly. The systems developed will be put into production as they are completed. A lower quality system would marginally affect the overall service. In the longer term, as more and more systems of lower quality are used, it would increasingly affect the company. The probability of such negative event is low (2). The activities concerned by the outsourcing contract are interdependent. The systems developed affect the other information systems. They also interact and affect activities of the firm. However, the suppliers considered are large, financially stable, and have extensive experience with software development activities. They have a lot to lose by providing low quality service.

Increased cost of service (cost escalation) was estimated to be medium-low (3) in this case. The costs of the systems developed can be subject to escalation. It is limited by the type of agreement sought by the client. The client wants a general agreement establishing the rules for pricing and management of the projects as they are approved. Therefore, it defines some upper limits for cost escalation. The probability of such cost escalation is medium-high (3). As in the first case, the opportunism of the supplier can manifest itself. Moral hazard and imperfect commitment are to fear. Again, 
the experience of the client with outsourcing and with the use of vendors helps reduce this probability.

Finally, the importance of the potential which would be due to the loss of organizational competencies is low (2). According to the managers who were interviewed in the study, expertise with software development is important in this organization, but it is not essential. The firm retain in-house skills related to overall planning of information systems resources. The more specialized (technical) skills are available on the market. The probability of loosing these competencies is medium (3). Indeed, many IS employees, discouraged by the perspective of seeing all the interesting projects given to external vendors decided to leave the firm. Some loss of skills is already apparent. Yet, these skills are not among the core competencies of the organization; therefore, their loss does not increase the probability of undesirable consequences for the firm.

A brief examination of Figure 3 indicates that some aspects of each project have higher levels of risk exposure than others. The next section briefly presents some of the measures the insurance company included in the contracts to lower the level of risk exposure of each project.

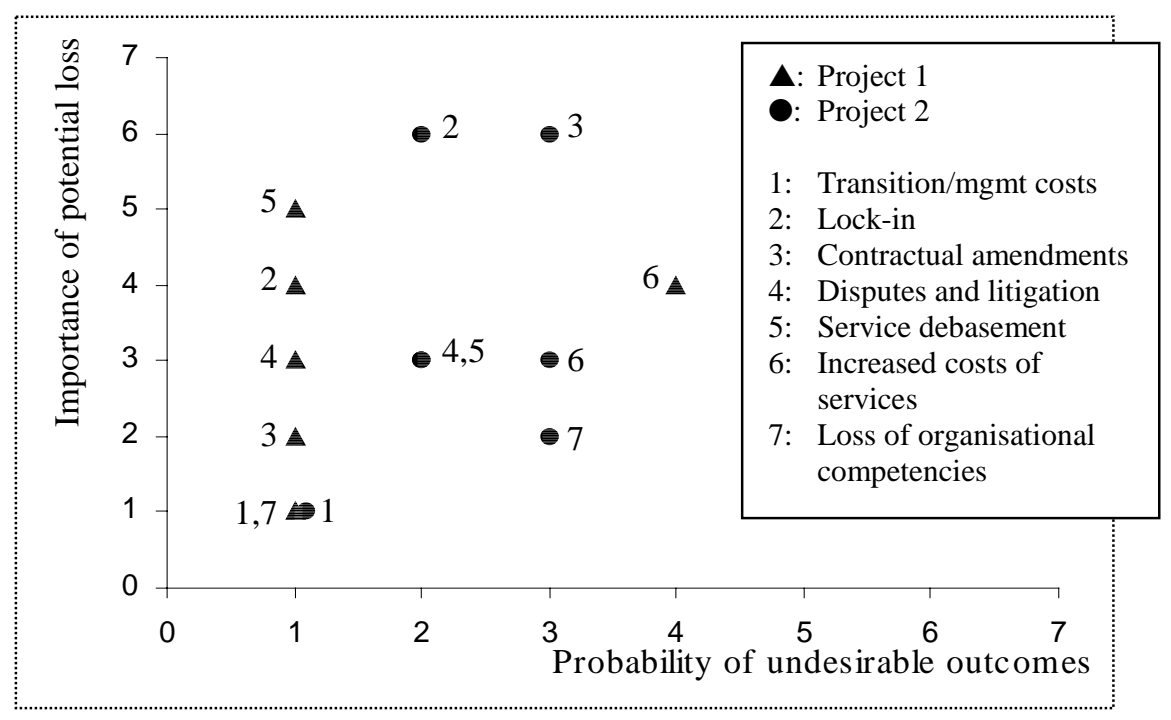

Figure 3 : Risk Level 


\section{Contract and Risk Management}

Strategic contracting deals with risk management by either reducing the probability of occurrence of an undesirable outcome, or by cutting the losses of such an outcome. Crafting, designing, negotiating and implementing a contract that will minimize the risk exposure of the client for a given level of benefits is an art. Efficient contracts structure the relationship between the client and the supplier in ways that are beneficial to both.

There is no exhaustive or explicit list of risk management measures and mechanisms. But, our examination of the two outsourcing contracts reveals that the client has purposively tried to manage the risk involved in outsourcing. We comment on several features of the contracts and show why these features should be expected to reduce the level of risk exposure to, one can only presume, reasonable levels.

The incidence of contracting on the level of risk exposure of each project, and for each undesirable outcome, can be seen on Figure 4, where the arrows indicate to what extent the measures adopted by the insurance company contributed to reduce the level of risk exposure.

\section{Contract 1 - Year 2000}

The Year 2000 contract involved three distinct possible undesirable outcomes with relatively high potential losses. These were : lock-in, service debasement, and increased costs of services. Examination of the contract reveals that each outcome was dealt with specifically. In each case, contract design is expected to reduce the probability of occurrence.

Consider first the lock-in problem. Lock-in is here limited to a few years since the project will end in year 2000 at the latest : the supplier cannot extract rents from the client beyond that point in time. Yet, the latter took several steps to protect himself against any rent-seeking from its supplier.

To check his dependence vis-à-vis the outsourcer, the client ensured that some of his own employees participated in each stage or the project. This assured the client that there was some retention of knowledge that would facilitate the transfer to another supplier in the advent of contractual difficulties.

Also, payments to the supplier were made conditional on approval of the work by the client. Since Y2000 compliance is either complete or not for each system, and since this can be ascertained and tested rather easily, tying payment to performance reduces the scope for opportunistic behavior on the part of the supplier. 
Protection against lock-in is finally achieved through sequential contracting. By splitting the work to be done in many sequential steps, each corresponding to a system to be modified, with its own specifications and pricing, the client achieves two ends: he ties the duration of the contract to verifiable performance on the one hand and he leaves open the possibility of walking out of the relationship if things were to take a bad turn. Since the contract does not contain any exclusive clause, the supplier's scope for opportunistic behavior is efficiently reduced by sequential contracting.

Lock-in represented a rather low probability, but high potential losses. Contracting clearly increased the tolerance of the client to that risk by reducing the stakes: the client managed an exit that would cut his losses.

In the case of service debasement, the main mechanism used by the client to reduce the probability of occurrence of this outcome was the inclusion of an important penalty for underperformance. This penalty is equal to five times the total value of the contract (which is a multi-million dollar contract). This serves two purposes: it elicits greater effort from the supplier, thus reducing the probability of occurrence of the undesirable outcome; and it serves as a type of insurance, thus reducing the monetary value of the consequences of the undesirable outcome.

Finally, in view of cost escalation, the client also sought to reduce the magnitude of losses. For instance, all proposals from the suppliers had to provide guaranteed rates. As mentioned before, each system is included in its own addendum. For each system, a preliminary analysis was conducted and an evaluation of the effort required was provided by the supplier. This evaluation represented an effort at capping prices. A $20 \%$ error margin was tolerated, which means that the final price could not be inflated by more than $20 \%$ from this first evaluation. Then, if the client agreed on the first evaluation, a detailed evaluation was done. A $10 \%$ error margin was then fixed on this detailed evaluation. The parties agreed ex ante on the evaluation method and relied on a detailed inventory of the various components, languages, platforms, size, complexity, testing environments, interactions with other systems, etc. Finally, to measure the quality of the work done, the client had a discretionary right of audit

Those contractual measures enabled the client to reduce the risk exposure of cost escalation significantly. And this was mainly achieved by capping the losses, thus by increasing the tolerance of the client to the inherent risks of outsourcing. The probability of such a loss was also reduced, mainly by the use of an addendum for each piece of the project. 
As shown by the arrows drawn in Figure 4, the potential losses associated with lock-in, service debasement and cost escalation are reduced, moving the coordinates of those outcomes down along the Potential Loss axis.

\section{Contract 2 - Application Development Partnership}

In the second contract, the risk exposure stemming from lock-in was reduced in two ways. The first one is multiple sourcing: the client uses of more than one supplier. As mentioned earlier, 29 suppliers made offers to the client. Three were selected to work concurrently.

Multiple sourcing makes room for competition between suppliers and provides an interesting yardstick for the assessment of individual performance. The sole presence of three suppliers actively involved in the operations seriously curtails the probability of being locked-in for the client.

The contract also includes specific measures that define the situations in which the client could prematurely terminate the agreement with one of the suppliers. These include the rendering of inadequate services, and the negligence of respecting any term of an agreement.

Similarly to the Y2000 contract, systems to be developed are consigned in addenda. This permits the client to include very specific quality measures for each system developed and to limit its commitment to any of the three suppliers to the system defined in the addendum.

Potential losses from lock-in are thus severely constrained, and the probability of being faced with rent-seeking behavior is also diminished. As indicated in Figure 4, this results in a repositioning of the lock-in outcome to the SouthWest, reducing the risk exposure of the client. 


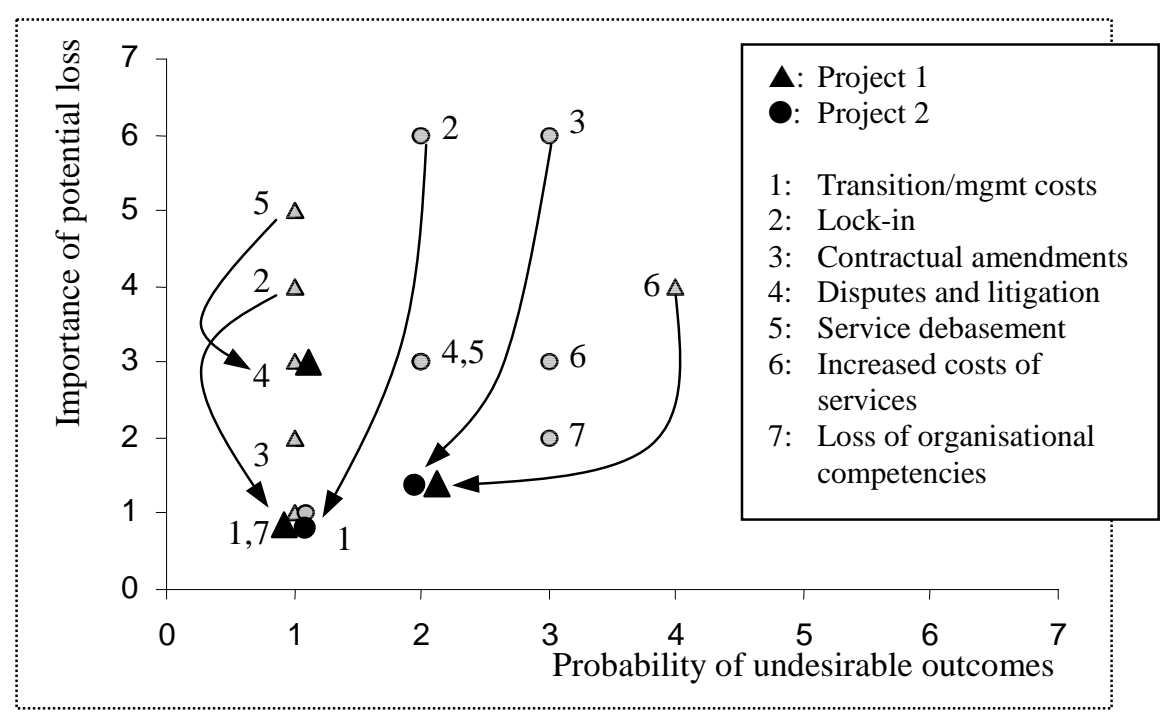

Figure 4: Risk Management

Renegotiation problems and costly contractual amendments are also handled through this separation of the assignments in addenda. Since these addenda are only written and added to the contracts when the systems (or parts of systems) are required, they are written at various times during the relationships with the suppliers. This enables the partners to actually modify their contract without costly renegotiations. It is an ongoing modification process that is included in the contract. It also allows the client to stop giving new assignments to a supplier who is perceived as inflating its costs or delivering poor quality services.

The outsourcers know this: they are thus more efficiently motivated and the probability of an undesirable outcome is decreased as well as the overall losses. Hence, the two outcomes with the highest risk exposure in contract 2 are dealt with in the contracting strategy with both Prudence and Tolerance strategies.

\section{Conclusion}

The two cases studied provide some support for the proposed risk management framework. First, it was possible, from the detailed data obtained about each case, to assess the level of risk exposure of each IT oustsourcing 
decision. Second, the risk management approaches adopted by the insurance company can be explained, and their appropriateness can be determined, using the framework.

More precisely, it was found that lock-in and service debasement in Contract 1 and lock-in and contractual amendments in Contract 2 were outcomes with high levels of risk exposure. Contracting strategies of the Tolerance and Prudence types were implemented to cope with these. On the other hand, many undesirable outcomes - such as unexpected transition costs, costly disputes and the loss of organizational competencies - only had low levels of risk exposure. They were plainly "acknowledged" and dealt with by the client only through surveillance and the inclusion in the contracts of standard features, such as the definition of an arbitration process. This could be assimilated to the proposed Monitoring Strategy.

Further empirical analysis is definitely warranted. First, our measure of risk exposure needs to be operationalized and validated. Second, a larger sample of outsourcing projects is required so as to lead to stronger conclusions. Finally, an examination of activities that were kept in-house would also shed light on the consistency of our framework. Would the level of risk exposure of these activities fall into the upper right quadrant? Intuition and the framework suggest that organizations refrain from outsourcing those activities associated with a prohibitive (non economical) benefit to risk exposure ratio. This suggests that some portion of the upper right quadrant is uneconomical for outsourcing, the risk exposure being much too high.

While the two cases examined do not constitute a thorough verification of the proposed framework, they nevertheless illustrate its fruitfulness, and provide enough empirical support to motivate further research. 


\section{References}

[1] Alchian, A.A., Demsetz, H., " Production, Information Cost and Economic Organization ," American Economic Review, 62, December 1972, pp.777-795.

[2] Anderson, J., Narasimhan, R., "Assessing Implementation Risk : A Methodological Approach," Management Science, Vol.25, No.6, June 1979, pp.512-521.

[3] Aubert, BA., Patry M., Rivard, S., "Assessing the Risk of IT Outsourcing" Proceedings of the Thirty-First Hawaii International Conference on System Sciences, Volume VI, Organizational Systems and Technology Track, Hugh Watson editor, Hawaii, janvier 1998, 685-693.

[4] Aubert, B.A., Patry, M., Rivard, S., "A Tale of Two Outsourcing Contracts," Cahier du GReSI 97-05, 1997.

[5] Barki, H., Rivard, S., Talbot, J., "Toward an Assessment of Software Development Risk," Journal of Management Information Systems, Volume 10, Number 2, Fall 1993, pp. 203-225.

[6] Barzel, Y., "Measurement Cost and the Organization of Markets ,"Journal of Law and Economics, 25, April 1982, pp.27-48.

[7] Boehm, B, B.W., Software Risk Management, IEEE Computer Society Press, Los Alamitos, California, 1989.

[8] Boehm, B.W., "Software Risk Management : Principles and Practices," IEEE Software, January 1991, pp.32-42.

[9] Cross, J., "IT Outsourcing : British Petroleum's Competitive Approach," Harvard Business Review, May-June 1995, pp.95-102.

[10] Dorn, P. "Selling One's Birthright," Information Week, No.241, October 16, 1989, p.52.

[11] Earl, M.J., "The Risks of Outsourcing IT," Sloan Management Review, Spring 1996, pp.26-32.

[12] Eisenhardt, K. " Agency Theory: An Assessment and Review," Academy of Management Review, Vol.14, No.1, 1989, pp.57-74.

[13] Gack, G., "A Cautionary Tale," Computerworld, September 12, 1994, pp.136-136.

[14] Grossman, S., Hart, O., "The Costs and Benefits of Ownership :A Theory of Vertical and Lateral Integration, " Journal of Political Economy, 94, 1986, pp.691-719. 
[15] Gupta, U., Gupta, A., "Outsourcing the IS Function : Is It Necessray for your Organization?," Information Systems Management, Summer 1992, pp.44-50.

[16] Huff, S. L., "Outsourcing of Information Services," Business Quarterly, Spring 1991, pp.62-65.

[17] Lacity, M.C., Hirschheim, R., Information Systems Outsourcing, John Wiley \& Sons, New York, 1993.

[18] Lacity, M.C., Willcocks, L.P., Feeny, D.F., "IT Outsourcing : Maximize Flexibility and Control," Harvard Business Review, May-June 1995, pp.84-93.

[19] Langlois, R.N., Robertson, P.L., "Networks and Innovation in a Modular System: Lessons from the Microcomputer and Stereo Component Industries, Research Policy, vol. 21, 1992, 297-313.

[20] Linerooth-Bayer, J., Wahlstrom, B., "Applications of Probabilistic Risk Assessments : the selection of Appropriate Tools," Risk Analysis, Vol.11, No.2, 1991, pp.239-248.

[21] MacCrimmon, K.R., Wehrung, D.A., Taking Risks : The Management of Uncertainty, The Free Press, New York, 1986.

[22] Mahoney, D., Confessions of a Street-Smart Manager, New York : Simon \& Shuster, 1988.

[23] Nam, K., Rajagopalan, S., Rao, H.R., Chaudhury, A., "A Two-Level Investigation of Information Systems Outsourcing," Communications of the ACM, Vol.39, No.7, July 1996, pp.37-44.

[24] Nelson, P., Richmond, W., Seidman, A., "Two Dimensions of Software Acquisition," Communications of the ACM, Vol.39, No.7, July 1996, pp.29-35.

[25] O'Leary, M., "The Mainframe Doesn't Work Here Anymore," CIO, Vol.6, No.6, June 1990, pp.77-79.

[26] Prahalad, C.V., Hamel, G., "The Core Competence of the Corporation," Harvard Business Review, May-June 1990, 79-91.

[27] Rao, H. R., Nam, K., Chaudhury, A., "Information Systems Outsourcing," Communications of the ACM, Vol.39, No.7, July 1996, pp.27, 28.

[28] Roberts, L., Process Reengineering, ASQC Quality Press, Milwaukee, Wisconsin, 1994. 
[29] Roll,R., "The Hubris Hypothesis of Corporate Takeovers,"Journal of Business, April 1986, pp.197-216.

[30] Sappington, D., "Incentives in Principal-Agent Relationships," Journal of Economic Perspectives, Vol.5, No.2, 1991, pp.45-68.

[31] Teece, D. J., Rumelt, R., Dosi, G., Winter S., "Understanding Corporate Coherence, Theory and Evidence", Journal of Economic Behavior and Organization, 23, 1994, 1-30

[32] Wideman, R.M., "Risk Management," Project Management Journal, September 1986, pp.20-26.

[33] Williamson, O.E., The Economic Institutions of Capitalism, The Free Press, New York, 1985. 


\section{Liste des publications au CIRANO *}

\section{Cahiers CIRANO / CIRANO Papers (ISSN 1198-8169)}

96c-1 Peut-on créer des emplois en réglementant le temps de travail ? / Robert Lacroix

95c-2 Anomalies de marché et sélection des titres au Canada / Richard Guay, Jean-François L'Her et Jean-Marc Suret

95c-1 La réglementation incitative / Marcel Boyer

94c-3 L'importance relative des gouvernements : causes, conséquences et organisations alternative / Claude Montmarquette

94c-2 Commercial Bankruptcy and Financial Reorganization in Canada / Jocelyn Martel

94c-1 Faire ou faire faire : La perspective de l'économie des organisations / Michel Patry

\section{Série Scientifique / Scientific Series (ISSN 1198-8177)}

98s-17 Learning Conditions in the Context of R\&D and Development Projects: Empirical Evidence from a Research Centre / Mario Bourgault et Hélène Sicotte

98s-16 Assessing the Risk of IT Outsourcing / Benoit A. Aubert, Michel Patry et Suzanne Rivard

98s-15 Determinants of Desired Career Paths among Canadian Engineers / Michel Tremblay, Thierry Wils et Caroline Proulx

98s-14 Why Is the Bid Price Greater than the Ask? Price Discovery during the Nasdaq Pre-Opening / Charles Cao, Eric Ghysels et Frank Hatheway

98s-13 "Informal Thinkering": How Is It Important? / Pierre J. Tremblay

98s-12 Organize to Generate Innovation: Tools to Measure Technical Change, Productivity and Change-Generating Efforts / Pierre J. Tremblay

98s-11 Worksharing in Québec : Five Case Studies / Michael Huberman et Paul Lanoie

98s-10 Predictors of Hierarchical Success for Male and Female Canadian Managers / Denis Chênevert et Michel Tremblay

98s-09 Managerial Career Success in Canadian Organizations: Is Gender a Determinant? / Denis Chênevert et Michel Tremblay

98s-08 Job Characteristics and the Form of Compensation / W. Bentley MacLeod et Daniel Parent

98s-07 Technological Capability and Productivity Growth: An Industrialized / Industrializing Country Comparison / Pierre J. Tremblay

98s-06 L'évolution du taux d'activité des femmes au Canada, 1976-1994 : Une analyse de cohortes / Paul Beaudry et Thomas Lemieux

98s-05 Dix exemples de rentabilité financière liés à une saine gestion environnementale / Paul Lanoie et Georges A. Tanguay

98s-04 Effects of Workers' Compensation: A Survey / Bernard Fortin et Paul Lanoie

98s-03 Dépendance à l'égard de l'aide sociale et réforme de la sécurité du revenu / Bernard Fortin

\footnotetext{
* Vous pouvez consulter la liste complète des publications du CIRANO et les publications elles-mêmes sur notre site World Wide Web à l'adresse suivante :

http://www.cirano.umontreal.ca/publication/page1.html
} 